\title{
Prevalence of dry eye among 195 patients with diabetes
}

\section{mellitus patients}

Received: 29/4/2015

Accepted: 1/11/2015

\begin{tabular}{ccc}
\hline Zana Ghany Hameed $*$ & Ahmed Abdulgani $* *$ & Abdulmajeed Abdulkadir $* * *$ \\
\hline Abstract &
\end{tabular}

Background and objective: Dry eye is a disorder of the tear film. There are significant associations between dry eye and environmental factors, autoimmune and chronic diseases like diabetes mellitus and rheumatoid disease. This study aimed to determine the prevalence of dry eye in patients with diabetes mellitus in patients attending Erbil and Rizgary Teaching hospitals in Erbil city.

Methods: A hospital-based cross-sectional study of 195 diabetic patients who presented to the department of ophthalmology, Rizgary and Erbil teaching hospitals, Erbil; from February 2011 to December 2011 was conducted. Detailed diabetic history was recorded. Assessment of anterior segment via slitlamp biomicroscopy was done. The examination of dry eye included Schirmer's test, tear break-up time and fluorescein dye

Results: From total 195 patients, eighty-one (41.5\%) of them had dry eye. The prevalence of dry eye among older ages ( $\geq 60$ years) was $49 \%$, which was higher than younger ages ( $<60$ years). The dry eye had a higher percentage in males than females $(44.7 \%$ and $39.1 \%$, respectively). Those who had diabetes mellitus for $<10$ years recorded $36.6 \%$ dry eyes, however, those who had diabetes mellitus for $\geq 10$ years showed $50.7 \%$ dry eyes. On the other hand patients with good diabetic control $(\mathrm{HbA} 1 \mathrm{c}<7 \%)$ had a lower prevalence of dry eye than those of uncontrolled one $(\mathrm{HbA} 1 \mathrm{c} \geq 7 \%)$ with a percentage of $38.5 \%$ and $48.3 \%$, respectively.

Conclusions: There was a high prevalence of dry eyes among diabetic patients in Erbil city. The prevalence of dry eye is higher in those with duration of diabetes for more than ten years. There was no statistically significant difference between male and female. The sensitivity of tear break-up time test was higher than Schirmer's test for diagnosing dry eye.

Keywords: Diabetes Mellitus; Dry eye; Arbil city; Cross-sectional study.

\section{Introduction}

The Latest definition of dry eye according to the International Dry Eye Workshop report (DEWS) in 2007 is a multifactorial disease of the tears and ocular surface (Figure 1). ${ }^{1}$ The study of ocular surface manifestations during the course of diabetes mellitus (DM) has increased in recent years. Reported prevalence of dry eye in diabetics is diverse, for example, $47 \%-67 \%$ of diabetic patients have primary corneal lesions during their lifetime. ${ }^{2}$ Qualitatively, abnormalities in tear secretion seem to be relevant to the development of diabetic keratoepitheliopathy such as superficial punctuate keratitis, recurrent corneal erosions and persistent epithelial defects. ${ }^{3}$ Autonomic dysfunction may be responsible for dry eye in DM. Aldose reductase, which is the first enzyme in sorbitol pathway, may also be involved. Correlation was found between the glycated hemoglobin ( $\mathrm{HbA1c})$ and the presence of dry eye syndrome. ${ }^{4}$ Decrease in sensitivity of the cornea in DRP was reported by Downie and Newell in $1961 .^{5}$ Higher levels of Nitric oxide (NO) were found in the aqueous humour of

* Erbil Directorate of Health, Erbil, Iraq.

** Department of Surgery, College of Medicine, Hawler Medical University, Erbil, Iraq. 
http://dx.doi.org/10.15218/zjms.2016.0033

diabetic patients and this may induce inflammatory reactions that cause cell damage. ${ }^{6}$ In diabetic patients suffering from dry eye, poor glycemic control (higher mean annual $\mathrm{HbA} 1 \mathrm{c}$ level) lead to higher annual consumption of ocular lubrication, regardless of age. ${ }^{7}$ Inspection of tear meniscus between the globe and the lower eyelid, tear break-up time, deficiency of lipid, mucin and aqueous tears will decrease the tear film stability and shorten the time interval between the opening of the eye and the appearance of dry spots. ${ }^{8}$ Fluorescein is a large molecule used to evaluate epitheliopathy. It pools in epithelial erosions and stains exposed basement membrane. ${ }^{9}$ Aquous tear production can be assessed in a variety of ways. Most widely used is Schirmer's test with its details were first published in $1903 .^{10}$ The patient report of dry eye symptoms tends to be more reliable and accurate than many dry eye clinical tests. This has led to a reliance on the symptom-based diagnosis of dry eye. ${ }^{11}$ The most basic therapeutic principle is the education of the patient to help him or her understand the need for the recommended therapy. ${ }^{12}$ Every clinician is familiar with the considerable discrepancy between the subjective complaints of patients and the clinical tests available to assess dry eye. Frequently the results of Schirmer's test, tear film break-up time and fluorescein staining do not correlate in clinical trials. Holy et al. concluded that subjective assessments and objective diagnostic tests have clinical utility as diagnostic tools in tear film disorders. ${ }^{15}$ Advising patients to use preservative free ophthalmic solutions as preservatives can aggravate ocular surface disorders, avoidance of soft contact lenses as they decrease tear production possibly due to decreased corneal sensation, replacing the tear volume by supplement tear lubricant. This is often effective for the patient with mild to moderate dry eye. Punctal occlusion is the most often used method to preserve tears when supplementation of the tear film is inadequate to control the symptoms or signs of ocular surface damage. ${ }^{13}$ The present study was designed to determine the prevalence of dry eye in patients with diabetes mellitus among patients attending Erbil and Rizgary Teaching hospitals in Erbil city.

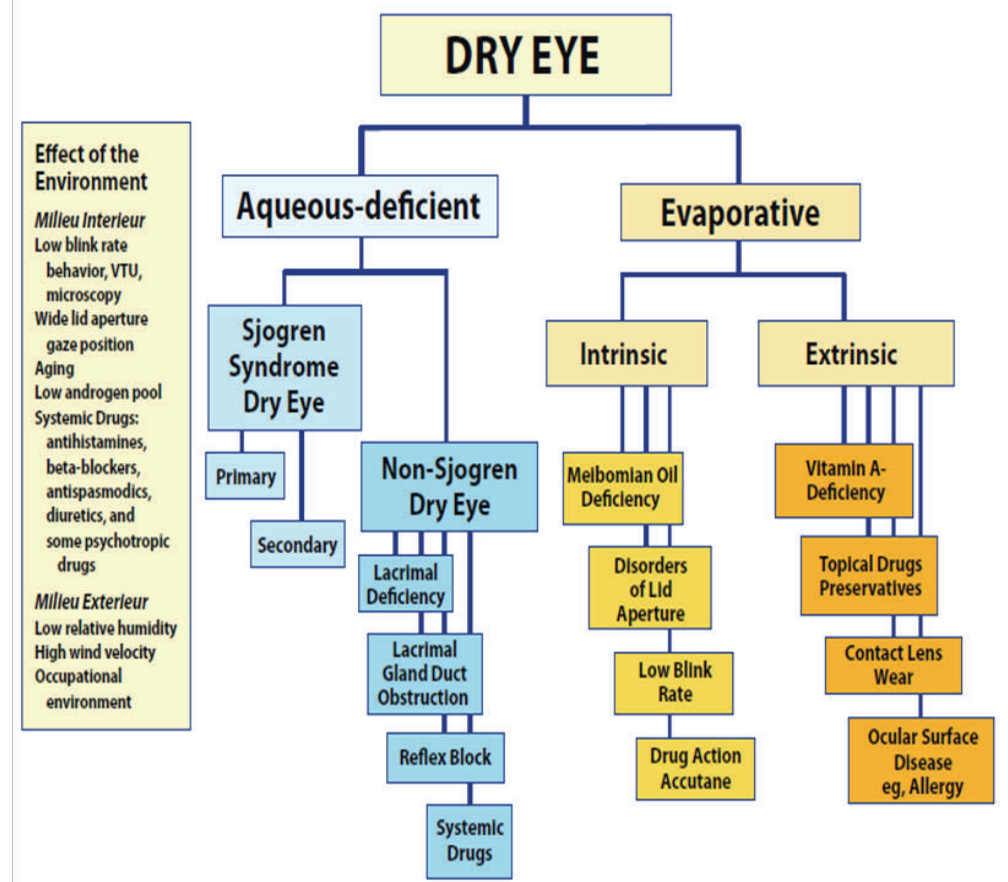

Figure 1: Major etiological causes of dry eye. (From Dry Eye WorkShop study 2007) 


\section{Methods}

This hospital-based clinical study to investigate the prevalence of dry eyes included 195 patients (390 eyes), of either sex and of all age groups, diagnosed to have diabetes mellitus (according to WHO diagnostic criteria for diabetes mellitus) and presented to the Department of Ophthalmology, Rizgary and Erbil Teaching Hospitals, Erbil, Iraq from February to December 2011. Twelve cases were excluded because of extraneous factors that would influence the prevalence of dry eye in diabetics. After obtaining informed consent, detailed history regarding the patient and his disease were recorded from participants, a questionnaire of ocular symptoms relating to dry eye was used. A brief general and systemic examination was carried out, with ocular examination included recording visual acuity, with complete slitlamp examination. A dry fluorescein strip was touched to the inferior fornix with the patient looking up without using anesthetic drops. The cornea was scanned under slitlamp using blue cobalt filtered light; value of $<10$ seconds was taken as abnormal. Schirmer's test I (basal and reflex tearing) was performed by placing a strip of filter paper in the inferior fornix, after 5 minutes was measured. Wetting of $\leq 10 \mathrm{~mm}$ was taken as abnormal. The following types of diagnostic parameters can identify the global features of dry eye disease. ${ }^{16}$ Symptoms (Questionnaires) Signs (Staining to identify ocular surface damage), Diagnostic tests (Tear break up time to assess tear instability and Schirmer's test). According to the Report of the National Eye Institute/ Industry workshop on Clinical Trials in Dry Eyes, ${ }^{14}$ dry eye is defined as having one or more symptoms along with one or more positive clinical findings (based on slitlamp examination) and one or more positive clinical tests (tear breakup time of $\leq 10$ seconds, Schirmer's test score $\leq 10$ $\mathrm{mm})$. The study was approved by the Research Ethics Committee of the College of Medicine, Hawler Medical University.
The statistical package for the social sciences (version 18) was used for the analysis of the data and Microsoft Excel has been used to generate graphs with tables. Chi-square test of association was used to show the association between dry eye with signs and symptoms. A $P$ value of $\leq 0.05$ was considered as statistically significant.

\section{Results}

\section{Participant characteristics:}

As it is shown in Table 1, a total of 195 diabetic patients participated in this study of which $34(17.4 \%)$ were type I diabetes and 161 (82.6\%) were type II diabetes. The difference in dry eye prevalence between type I DM and type II DM was statistically non-significant $(P=0.7)$. The mean age $( \pm$ SD) of the participants was $46.87 \pm 17.6$ years. The frequency of patients according to age; $50(25.6 \%)$ patients were $<40$ years old, $41(21 \%)$ patients were between 40 to 49 years old, $53(27 \%)$ of them were between 50 to 59 years old and the remaining $51(26 \%)$ patients were 60 years old and above. The highest percentage $(49 \%)$ of dry eyes was found in the older age group 60 years and more while the lowest percentage $(36.6 \%)$ of dry eyes was found in the age group 40 to 49 years old patients and the difference between them regarding dry eye prevalence was statistically non-significant $(P=0.63)$. Among 195 diabetic patients, 85 (43.6\%) were male and $110(56.4 \%)$ were female. 38 out of 85 male patients and 43 out of 110 female patients were found to have a dry eye with rates $44.7 \%$ and $39.1 \%$, respectively. The statistical difference between them was nonsignificant $(P=0.46)$. There were 71 $(36.4 \%)$ cases had diabetes for ten years or more, but $124(63.5 \%)$ patients for less than ten years. We found that the prevalence of dry eye in those who had diabetes for longer duration is higher than those who had the disease 
for shorter duration with rates of $50.7 \%$ difference between them was significant and $36.6 \%$, respectively. The statistical $(P=0.05)$.

Table 1: Prevalence of dry eye by age, sex, duration of DM, HbA1c and type of DM.

Variables

$\mathbf{N}$

Dry eye

No.

(\%)

$P$ value

\section{Type of DM}

Type I

34

13

(38.2)

Type II

161

68

0.7

Sex

Male

85

38

(44.7)

Female

110

43

0.46

(39.1)

\section{Duration of diabetes(years)}

$<10$

124

45

$10+$

71

36

0.05

(50.7)

HbA1c

$<7 \%$

$\geq 7 \%$

60

29

0.21

Age (years)

$<40$

50

20

$40-49$

41

15

50-59

53

21

(39.6)

$60+$

51

25

(49.0)

Total

195

81 
Of 195 diabetics patients with good diabetic control 52 (38.5\%) showed dry eyes, while the uncontrolled ( $\mathrm{HbA} 1 \mathrm{c} \geq 7 \%$ ) group had 29 (48.3\%) dry eye patients. The statistical difference between them was non-significant $(P=0.21)$. At presentation, 88 eyes $(22.5 \%)$ had dry sensation, of which 78 (88.6\%) were dry; 98 (25\%) eyes had gritty sensation, of which 74 (75.5\%) were dry; 116 (29.7\%) eyes had burning sensation, of which 78 (67.2\%) were dry; watering in $90(23 \%)$ eyes, of which $74(82.2 \%)$ were dry; redness in $104(26.6 \%)$ eyes, of which $86(82.7 \%)$ were dry; and stuck eyes compromised $82(21 \%)$ eyes, of which $70(85.4 \%)$ were dry. The statistical difference between them was highly significant $(P<0.001)$ as shown in Table 2. Table 3 shows that all dry eyes had reduced tear meniscus and superficial punctate keratopathy.

Table 2: Prevalence of dry eye by symptoms (No. = 390 eyes).

\begin{tabular}{lcccc}
\hline Variables & $\mathbf{N}$ & No. & Dry eye & \multirow{2}{*}{$\boldsymbol{P}$ value } \\
\hline Dry sensation & 88 & 78 & $(88.6)$ & \\
Yes & 302 & 84 & $(27.8)$ & $<0.001$ \\
No & & & & \\
Gritty sensation & 98 & 74 & $(75.5)$ & $<0.001$ \\
Yes & 292 & 88 & $(30.1)$ & \\
No & & & & \\
Burning sensation & 116 & 78 & $(67.2)$ & $<0.001$ \\
Yes & 274 & 84 & $(30.7)$ & \\
No & & & & \\
Watering & 90 & 74 & $(82.2)$ & $<0.001$ \\
Yes & 300 & 88 & $(29.3)$ & \\
No & & & & \\
Red eye & 104 & 86 & $(82.7)$ & $<0.001$ \\
Yes & 286 & 76 & $(26.6)$ & \\
No & & & & \\
Stuck eye & 82 & 70 & $(85.4)$ & $<0.001$ \\
Yes & 308 & 92 & $(29.9)$ & \\
No & 390 & 162 & $(41.5)$ & \\
Total & & & &
\end{tabular}

Table 3: Prevalence of dry eye by signs (No. $=390$ eyes).

\begin{tabular}{lcccc}
\hline Variables & N & No. & $\begin{array}{c}\text { Dry eye } \\
(\%)\end{array}$ & P value \\
\hline Tear meniscus & & & & \\
Normal & 284 & 56 & $(19.7)$ & $<0.001$ \\
Reduced & 106 & 106 & $(100.0)$ & \\
$\quad$ Conjunctiva & & & & \\
Normal & 336 & 116 & $(34.5)$ & $<0.001$ \\
$\quad$ Congested & 54 & 46 & $(85.2)$ & \\
$\quad$ Cornea & & & & \\
Normal & 255 & 27 & $(10.6)$ & $<0.001$ \\
SPK & 135 & 135 & $(100.0)$ & \\
Total & 390 & 162 & $(41.5)$ & \\
\hline \hline
\end{tabular}




\section{Discussion}

In this study, the diagnosis of dry eye is based on symptoms, signs, fluorescein stain and diagnostic tests (tear break up time with Schirmer's test). There were a number of patients who had no symptoms or signs of ocular surface damage, but they had abnormal tear break up time or Schirmer's values. Those were not fit to our inclusion criteria for selecting dry eye patients. As far as the signs of ocular damage can be a late presentation in the course of dry eye, hence we may miss the milder forms of this disease. In the present study, the prevalence of dry eyes was found to be $41.5 \%$. In type I diabetes it was $38.2 \%$, and type II it was $42.2 \%$. As shown in Table 4, the prevalence of dry eyes in diabetes reported by various other studies is compared with the present study. The prevalence of dry eyes varies from $19.8 \%$ to $54 \%$, thereby showing wide disparity. Much of this disparity stems from the fact that there is no standardization of the types of patients selected for the study. The difference of dry eye diagnostic criteria is another issue. In our study, we diagnosed dry eye on the base of at least one positive symptom, one positive sign associated with one positive test, while in Slis bury Eye Evaluation (Moss et al.) study, the diagnosis depended on one or more symptoms occurring often or all the time. ${ }^{19}$ Deference in the climate, for example, the study done in Iran shows higher prevalence as the climate is hotter than our locality. ${ }^{4}$ Men reported more dry eye symptoms $(44.7 \%)$ than women $(39.1 \%)$, a result that differs from Melbourne study by McCarty CA et al. ${ }^{20}$ and agrees with the SEE study by Schein OD et al. ${ }^{19}$ Possible explanation for this result is that male people work out door more than female. However, the statistical difference between male and female was not significant $(P=0.46)$. We might assume that diabetes induced dry eye has no sex predilection, thus weakening the effect of female sex on dry eyes. Besides the statistical nonsignificance $(P=0.63)$ between age and dry eye which give us a clue that dry eye inheritance may play a role in the disease independently of age, our finding of an association between older age ( $\geq 60$ years) and an increase in dry eye symptoms $(49 \%)$ is consistent $(P=0.63)$ with the Melbourne study. ${ }^{20}$ This is likely a result of normal changes in tear production and characteristics associated with advancing age. Reduction of tear volume and increases in evaporation have been noted in older people. ${ }^{21}$ Duration of diabetes was significantly associated with the prevalence of dry eyes in diabetic patients $(P=0.05)$, especially in those who had diabetes for more than ten years $(50.7 \%)$. The same pattern was found in both Manaviat et al. ${ }^{4}$ and Kein et al. $^{22}$ This result confirms the fact that most of the long-term complications of diabetes are well known to correlate with duration of the disease, dry eyes could also be a part of this. In present study uncontrolled diabetic patients with HBA1c $(\geq 7 \%)$ levels were found to be associated with higher percentage of dry eyes $(48.3 \%)$

Table 4: The present study`s prevalence of dry eyes in diabetes compared with other studies.

\begin{tabular}{lll}
\hline Authors & Place & Diabetic \\
\hline Moss et al. ${ }^{17}$ & United states & $19.8 \%$ in type II \\
Inoue et al. $^{3}$ & Japan - Tokyo & $22.8 \%$ \\
Peponis et al. $^{6}$ & Greece & $37 \%$ \\
Martin Goebbels. $^{18}$ & German & $37 \%$ in type I \\
Manaviat et al. $^{4}$ & Iran -Yazd & $54 \%$ type II \\
Present study & Erbil & $38.2 \%$ in type I diabetics and 42.2\% in type II \\
\hline \hline
\end{tabular}


than controlled one HBA1c $(<7 \%)$ with the percentage of dry eyes $(38.5 \%)$. Symptoms often do not correlate with signs of dry eyes. The patient report of dry eye symptoms tends to be more reliable and accurate than many dry eye clinical tests; in addition, the results of dry eye clinical tests tend to agree poorly with patient reported symptoms. This is likely because of significant variables associated with the reliability of many dry eye tests as well as symptom report, these factors lead to a dilemma in clinical, practice and research situations, making clinical decisions difficult regarding tests to be used and interpretation of those tests. ${ }^{11}$ The diabetic patients may exhibit dry eye signs with or without discomfort due to corneal neuropathy. ${ }^{9}$ Participants complained of burning sensation most often $(29 \%)$, followed by symptoms of red eye $(26 \%)$, and gritty sensation (25\%) these symptoms were reported more frequently compared with the other dry eye symptoms and were significantly related to clinical dry eyes.

\section{Conclusions}

The prevalence of dry eye is high $(41.5 \%)$ among diabetic patients in Erbil city. The prevalence of dry eye increases with increasing the duration of diabetes. Therefore, examination of dry eye should be an integral part of the assessment of diabetic eye disease.

\section{Conflicts of interest}

The authors report no conflicts of interest.

\section{References}

1. McCulley, Juan M, Stephen C. Maurizio R., Ikuko T. The definition and classification of dry eye disease: report of the Definition and Classification Subcommittee of the International Dry Eye Workshop 2007; 5(2):75-92.

2. Schutz RO, Van Horn DL, Peters MA, Klewin KM, Schutten WH. Diabetic keratopathy. Trans Am Ophthalmol Soc 1981; 79:180-99.

3. Inoue K, Kato S, Ohara C, Numaga J, Amano S, Oshika T. Ocular and systemic factors relevant to diabetic keratoepitheliopathy. Cornea 2001; 20 (8):798-801.
4. Manaviat MR, Rashidi M, Ardekani MA and Shoja MR. Prevalence of dry eye syndrome and diabetic retinopathy in type II diabetic patients. BMC Ophthalmology 2008; 8:10.

5. Downie AW, Newell DJ. Sensory nerve conduction in patients with diabetes mellitus and control. Neurology 1961; 11:876-82.

6. Peponis V, Papathanasiou M, Kapranou A, Magkou C, Tyligada A, Melidonis A, et al. Protective role of oral antioxidant supplementation in ocular surface of diabetic patients. $\mathrm{Br} J$ Ophthalmol. 2002; 86(24):1369-73.

7. Kaiserman I, Kaiserman N, Nakar S, Vinker Sh. Dry eye in diabetic patients. Am J Ophthalmol 2005; 139(3):498-503.

8. Sutphin JE, Dana MR, Florakis GJ, Hammersmith K, Reidy JJ, Lopatynsky M. External disease and cornea. Basic and clinical science course. American Academy of Ophthalmology; Section 8. San Francisco: American Academy of Ophthalmology The Eye M.D. Association; 2007; 61-70.

9. Obata H, Yamamoto S, Horiuchi H, Machinami R. Histopathologic study of human lacrimal gland. Statistical analysis with special reference to aging. Ophthalmology 1995; 102:678-86.

10. Schirmer O. Studien zur physiologie und pathologie der Tranenabsonderung und Tranenabfuhr. Graefes Arch Ophthalmol 1903; 56:197-291.

11. Nichols KK, Mitchell GA, Zadmik K. Frequency of dry eye diagnostic test procedures used in various modes of ophthalmic practice. Cornea 2002; 21:578-83.

12. Tsubota K, Nakamori K. Dry eyes and video display terminals. N Engl J Med 1993; 328(8):584.

13. Will DV, MeNally LM, Roth RE. Pyogenic granuloma complicating parasoltm silicone punctal plug occlusion: a series review. Invest Ophthalmol Vis Sci 2000; 41:S69.

14. Dimakara GV, Kumar P. Evaluation of dry eye status in diabetes mellitus and its correlation with diabetic retinopathy. RSSDI $33^{\text {rd }}$ conference; 2005.

15. Holy FJ, Lemp MA. Report of the National Eye Institute/ Industry workshop on Clinical Trials in Dry Eyes. CLAO J 1995; 21:221-32.

16. Born AJ. Diagnosis of dry eye. Surv Ophthalmol 2001; 45(suppl 2):S227-39.

17. Moss SE, Klein R, Klein BE. Incidence of dry eye in an older population. Arch Ophthalmol 2004; 122:369-73.

18. Martin Goebels. Tear secretion and tear film function in insulin dependent diabetics. BrJ Ophthalmol 2000; 84:19-21.

19. Schein OD, Munoz B, Tielsch JM, Bandeen-Rochek, West S. Prevalence of dry eye among elderly. AMJ Ophthalmol 1997; 124:723-8.

20. McCarty CA, Bansal AK, Livingston PM, Stanislavsky YL, Taylor HR. The epidemiology of 
Prevalence of dry eye among 195 patients .......

Zanco J. Med. Sci., Vol. 20, No. (2), 2016

http://dx.doi.org/10.15218/zjms.2016.0033

dry eye, Melbourne, Australia. Ophthalmology 1998; 105:1114-9.

21. Mathers WD, Lane JA, Zimmerman MB. Tear film changes associated with normal aging. Cornea 1996; 15:229-34.

22. Klein R, Klein BE, Moss SE. Prevalence of and risk of diabetic retinopathy when age at diagnosis is 30 or more years. Arch Ophthalmol 1984; 102:527-32. 